\title{
ANALYSIS OF CONTOUR ACCURACY AND PROCESS FORCES USING A CHAMBER-BORING-SYSTEM
}

\author{
R. Schmidt ${ }^{1 *}$, J. F. Gerken ${ }^{1}$, M. Fuß ${ }^{1}$, D. Biermann ${ }^{1}$ \\ ${ }^{1}$ Institute of Machining Technology, TU Dortmund University, Baroper Straße 303, 44227 Dortmund, Germany \\ *Corresponding author; e-mail: robert.schmidt@isf.de
}

\begin{abstract}
Deep hole drilling is a metal cutting method for producing primary cylindrical deep bores with a length-todiameter ratio larger than $I / D=10$. Due to the increasing interest of different branches of the industry in inner contoured workpieces, the Institute of Machining Technology (ISF) and the BGTB GmbH developed a chamber boring system, which allows to contour boreholes in axial and radial directions. This paper presents the influence of different cutting speeds, feeds and workpiece materials on the contour accuracy and the mechanical tool loading.
\end{abstract}

\section{Keywords:}

Deep hole drilling; Manufacturing process; Chamber boring; Contour measurement; Non-circular profiles; Experimental approaches in machining

\section{INTRODUCTION}

The use of inner contoured tubes made of metallic materials with circular and non-circular profiles offers a great economical and ecological potential for a large number of industrial sectors [Biermann 2018]. The most important users are the aviation industry as well as the oil industry. The huge advantage for the aviation industry is the weight reduction of landing gears for aircrafts compared to massive components [Buse 1994]. Moreover, the inner contoured tubes with non-circular profiles can be used for the oil exploration as a stator in mud motors. Mud motors, which are named after their creator "Moineau", are based on the inverted functioning of a progressive cavity positive displacement pump and are mainly used in drill-heads for the gas exploration as shown in Fig. 1a).

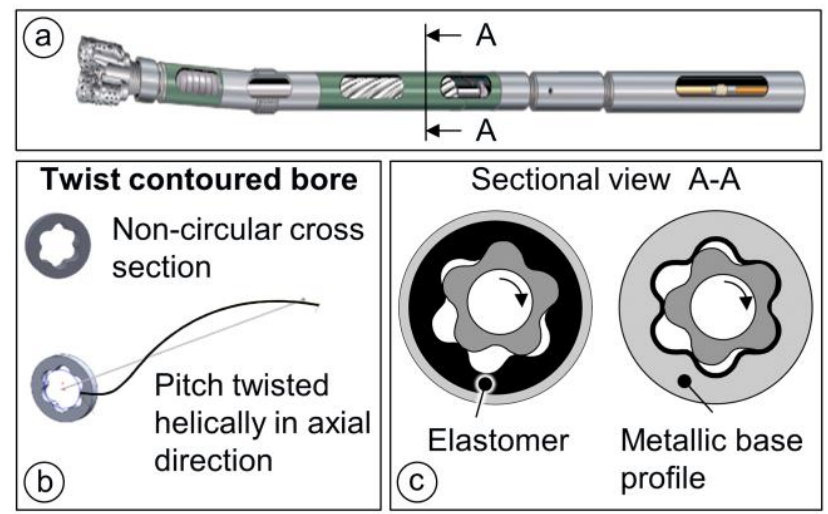

Fig. 1: Possible usage of the non-circular profile [Fuß 2016].

The screw shaped rotor and the hollow stator with a noncircular cross section are the most important parts of the
Moineau-motor as shown in Fig. 1b) and Fig. 1c) [Baker Hughes 2002]. While it is possible to machine the screw shaped rotor, the non-circular cross section of the hollow stator consists often of elastomer (Fig. 1c, left), especially for smaller diameters $(D<75 \mathrm{~mm})$. Only for very large diameters a metallic base profile with a thin elastomer layer is possible. Stators with a metallic basic profile and equipped with an elastomer layer have an efficiency enhancement up to $100 \%$ compared to elastomer profiles [Maurer 2000, Fuß 2016].

According to the current state of technology, it is not economical to produce the required metallic base profile in smaller diameters with standard machining processes [Denkena 2016, Heisel 1989]. Other potential manufacturing processes such as tube drawing are very time-consuming, cost-intensive and inflexible [Bottos 2003]. In response to the increasing demands on long tubes with a complex inner contour, the chamber boring system was developed.

\section{EXPERIMANTAL SETUP}

\subsection{Material}

The materials used for the chamber boring experiments were two steel alloys (42CrMo4+QT/AISI4140, C60/AISI1060) and one aluminium alloy (AIMgSi0,5/EN AW-6060). The round bars had a diameter of $D=80 \mathrm{~mm}$ a length of $\mathrm{I}=250 \mathrm{~mm}$ and were pre-drilled and honed with a bore diameter $D_{B}=46 \mathrm{~mm}$ and $a$ tolerance range $\mathrm{H} 7$ [DIN EN ISO 286-1:2019-02]. The mechanical properties of the materials are displayed in Tab. 1. 
Tab. 1: Mechanical properties of the test materials [Saarstahl 2019a, Saarstahl 2019b, Delta 2019].

\begin{tabular}{cccc}
\hline Material & AISI 4140 & AISI 1060 & EN AW-6060 \\
\hline $\mathrm{Rm}_{\mathrm{m} \text { in MPa }}$ & $900-1100$ & $>670$ & $\geq 190$ \\
\hline $\begin{array}{c}\mathrm{R}_{\mathrm{p} 0,2} \text { in } \\
\mathrm{MPa}\end{array}$ & $\geq 650$ & $\geq 340$ & $\geq 150$ \\
\hline $\begin{array}{c}\text { Hardness } \\
\text { in HB }\end{array}$ & $\leq 255$ & $\leq 241$ & $\geq 65$ \\
\hline $\begin{array}{c}\text { Density in } \\
\mathrm{kg} / \mathrm{m}^{3}\end{array}$ & 7.9 & 7.8 & 2.7 \\
\hline $\begin{array}{c}\text { Heat } \\
\text { treatment }\end{array}$ & $\begin{array}{c}\text { Quenched } \\
\text { \& tempered }\end{array}$ & Normalized & $\begin{array}{c}\text { Precipitation } \\
\text { Hardened }\end{array}$ \\
\hline
\end{tabular}

\subsection{Components of the chamber boring system}

The three main components of the chamber boring system are the drill head, the special boring bar and the tool-/slidedrive. The drive is located on a console which is mounted to a deep hole drilling machine Giana GGB 560 (Guiseppe Giana s.r.I, Magnago, Italy) at the ISF in Dortmund (Fig. 2). Due to the modular construction the deep hole drilling machine is not impaired in its original function. The console holding the complete drive and the gearbox, for the gear reduction of the feed $f$, is mounted on the back of the too slide and is attached to the casing bar and the internal oscillating pole. The main function of the drive is to transfer the rotary movement of the tool spindle into a translational extension movement. The movement is transmitted by a drive pulley on which a rail-guided plate is mounted.

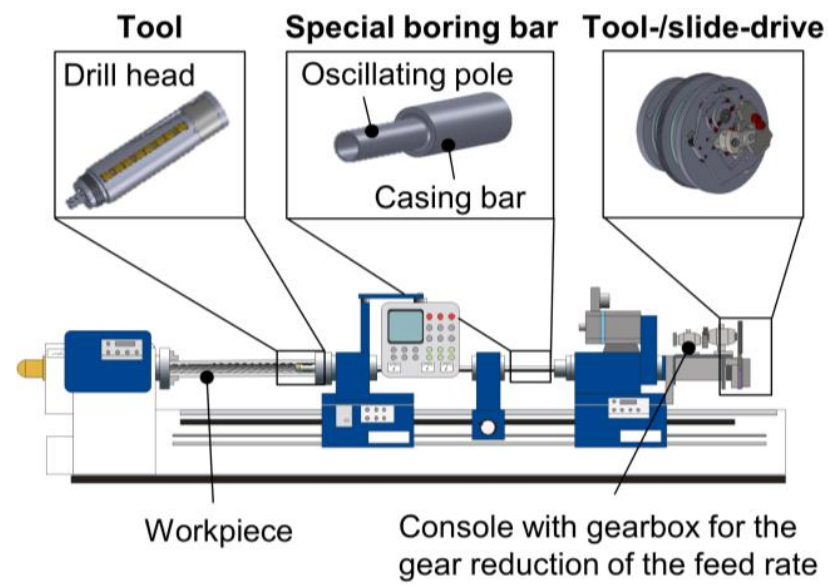

Fig. 2: Chamber boring system adapted to the Giana GGB 560 [Fuß 2016].

The drive pulley in Fig. 3a) is connected to the tool spindle and rotates as the drill head does. On the drive pulley, the slide plate is mounted on ball rail guides so that it can only move along these guides during rotation. The cam roller shaft is connected to end of the guided slide plate with an adjustable claw. This shaft is the connection to the profile shown in the cam disk in Fig. 3b). The cam roller is guided through the profile during a rotation of the drive pulley. Since the slide plate and the cam roller are connected, the slide plate covers the radial difference, between two sequential points of the profile.

The coupling of the cam disk to the feed motor via the gearbox generates the pitch of the profile. The cam disk, which embodies the shape of the profile to be produced, is rotated once per $I_{f}=500 \mathrm{~mm}$ of feed travel.

The adjustable claw converts the translational motion to oscillating motion and transmits it to the oscillating pole. An excenter, connected to the oscillating pole inside the drilling head, alternates the positioning of the cutting edge. An adjustable mechanism located at the claw adjusts the generated stroke. The process is being executed by pulling the tool through a honed bore, in which the tool is guided and supported by its guide pads.

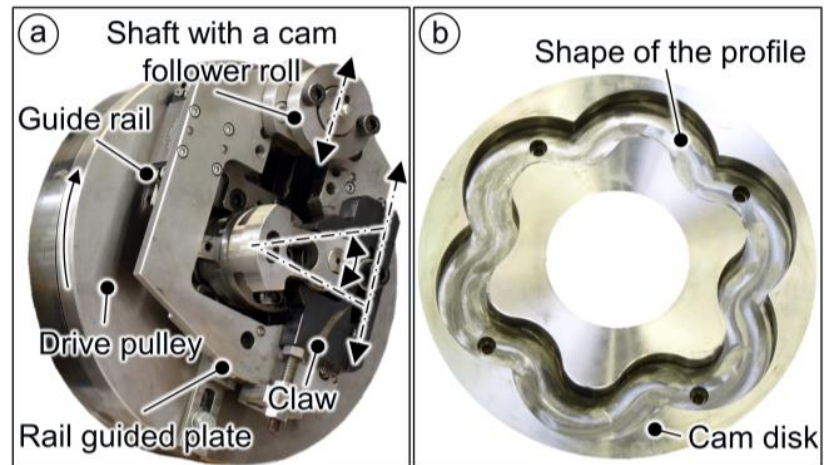

Fig. 3: Tool-/slide-drive with cam disk [Fuß 2016].

Due to the constant change of the diameter, the cutting speed $v_{c}$ varies throughout the entire process. Fig. 4 shows the position of the cutting edge in the profile and the resulting velocity components. The resulting cutting speed $v_{c r e s}$ is composed of a constant and a variable speed share.
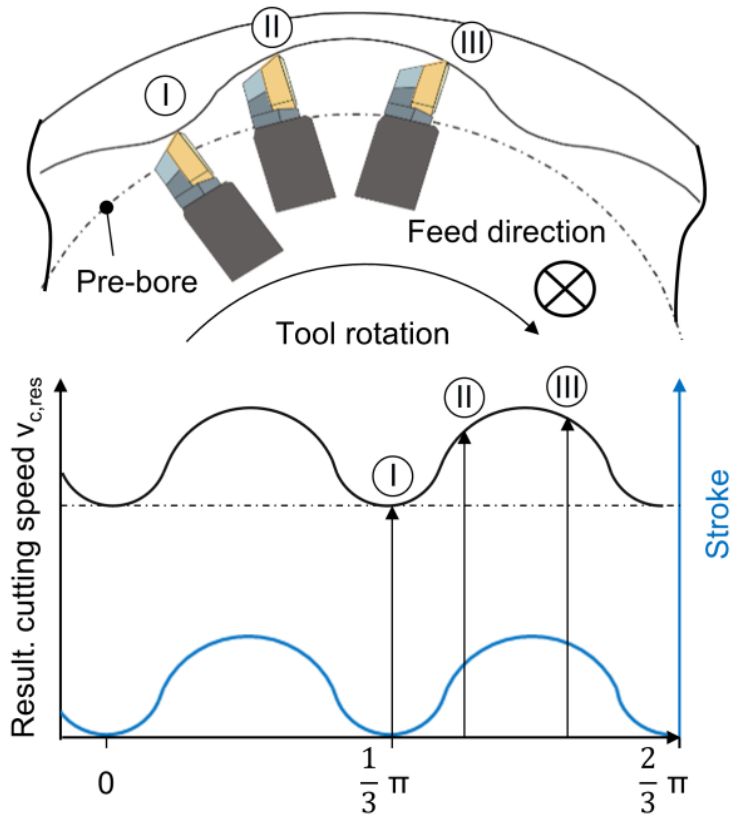

Position in the profile

Fig. 4: Cutting speed $v_{c}$ in relation to the stroke.

The second parameter that affects the cutting speed $\mathrm{v}_{\mathrm{c}}$ is the rotation speed of the tool spindle. The spindle speed is limited to $125 \mathrm{~min}^{-1}$. The reason for the limitation is justified by the mechanical drive concept. The cam disk is enlarged by a factor of three compared to the nominal workpiece contour to ensure a reliable transmission of the process forces. Fig. 5 shows the curve of the resulting acceleration of the rail guided plate for one chamber and a rotation speed of $80 \mathrm{~min}^{-1}$. The black arrows in the image illustrate the direction and amount of the resulting acceleration at the respective time. The maximum accelerations are at the inflection points of the profile, where the cam follower roll moves from the concave area to the convex area of the profile. 


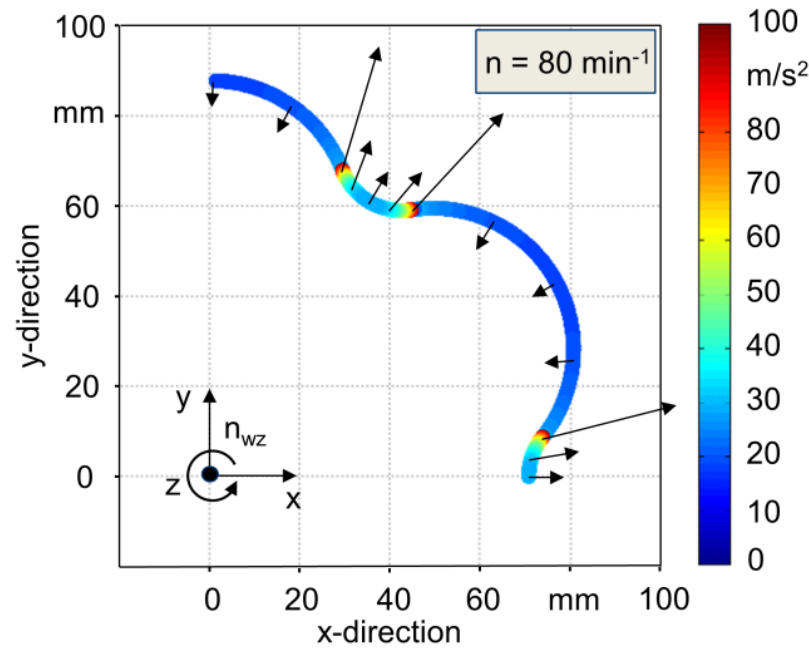

Fig. 5: Resulting acceleration ares of the rail guided plate.

Fig. 6 shows the maximum resulting velocity and maximum resulting acceleration for different spindle speed. The increase of the spindle speed causes a linear increase of the velocity and a quadratic increase of the acceleration. Due to the high moving masses and the high accelerations at the rail guided plate, an increase of the tool spindle speed causes an enormous increase of the mechanical loads at the drive.

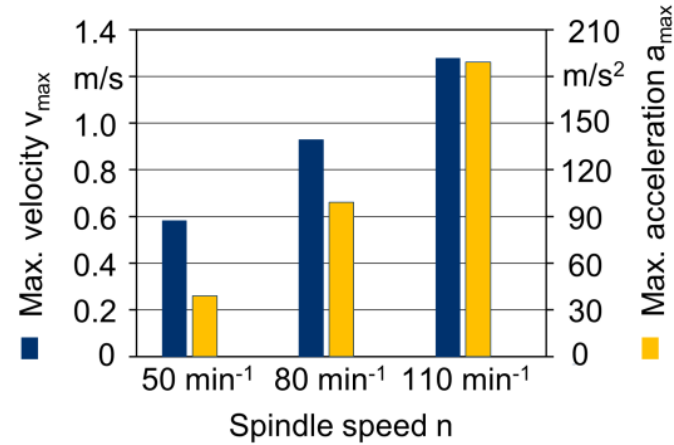

Fig. 6: Maximum accelerations $a_{\max }$ and velocity $v_{\max }$ of the rail guided plate.

\subsection{Cutting tools}

Three different cutting tools were used during the tests. All cutting tools were custom-made by Pokolm (Pokolm Frästechnik $\mathrm{GmbH} \&$ Co. KG). The details of the cutting edges used are shown in Tab. 2.

Tab. 2: Properties of the used inserts

\begin{tabular}{cccc}
\hline Tool & A & B & C \\
\hline $\mathrm{I}_{\mathrm{k}, \mathrm{S}, \mathrm{r}_{\mathrm{c}}\left(^{*}\right)}$ & $10 / 5 / 1 \mathrm{~mm}$ & $10 / 5 / 1 \mathrm{~mm}$ & $10 / 5 / 1 \mathrm{~mm}$ \\
\hline Grade & $\mathrm{K} 10$ & $\mathrm{~K} 10$ & $\mathrm{~K} 10$ \\
\hline Coating & $\begin{array}{c}\text { Polished } \\
\text { rake face }\end{array}$ & $\mathrm{PVTi}$ & $\mathrm{PVTi}$ \\
\hline $\begin{array}{c}\text { Cutting } \\
\text { edge }\end{array}$ & rounding & rounding & chamfer \\
\hline \multicolumn{2}{c}{$\left(^{*}\right)$ edge length $\left(\mathrm{l}_{\mathrm{k}}\right)$, thickness $(\mathrm{s})$, corner radius $\left(\mathrm{r}_{\mathrm{c}}\right)$} \\
\hline
\end{tabular}

\subsection{Measurement of the non-circular cross section area of the profile}

Seven parameter variations with a length of $I_{f}=10 \mathrm{~mm}$ were performed in one sample. Due to the pitch of the profile, undercuts result in the probe, which made the measurements with the coordinate measuring machine more difficult. Because of this, the samples were sawed into $\mathrm{I}=10 \mathrm{~mm}$ thick discs so that one disc corresponds to one test. These discs could be measured on the Zeiss Prismo portal measuring device (Carl Zeiss AG) as shown in Fig. 7.

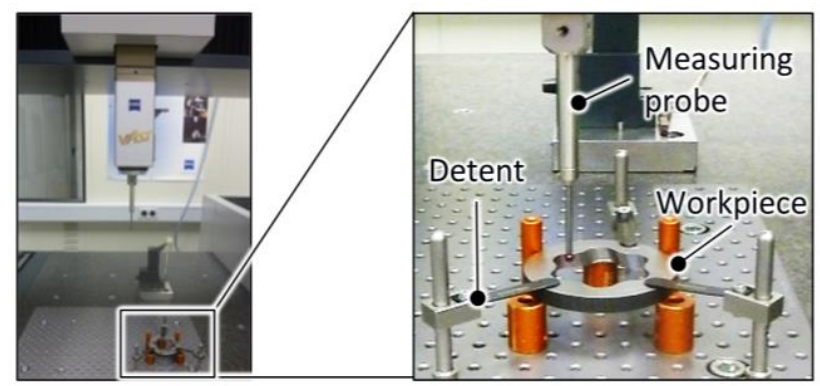

Fig. 7: Coordinate measuring machine with clamped profile sample.

The cross-section area of the profile was calculated through the measured contour. To obtain the surface produced by the chamber boring system the area of the pre-drilled diameter $\left(D_{B}=46 \mathrm{~mm}\right)$ was subtracted from the crosssection area. The resulting profile surfaces were used to estimate the influence of the process-parameters on the machined profiles in chapter 3.1.

\subsection{Measurement of tool load}

The tool load was determined by measuring the torsion of the oscillating pole and the casing bar with strain gauges. Due to the coupling of the pole and the bar and the rotation of the tool spindle, a wireless data transmission was required. The applied measurement technology is shown in Fig. 8.

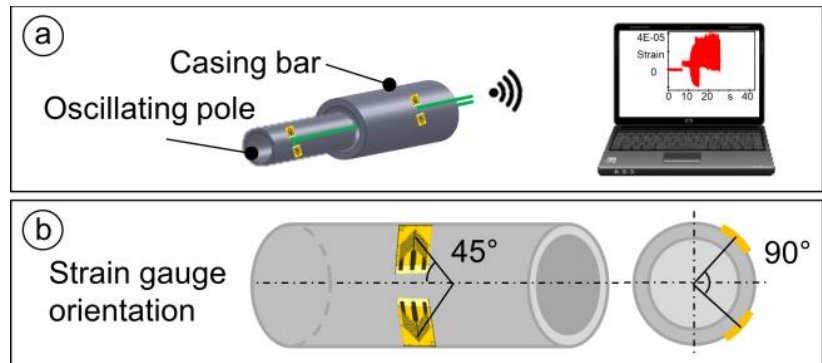

Fig. 8: Structure of the measurement technology.

The measuring signal was transmitted via a Wi-Fi to a measuring computer and could be displayed during machining, as shown in Fig. 8a). In order to realize a Wheatstone bridge, the strain gauges were mounted at an angle of $\alpha=45^{\circ}$ to the drilling axis and orthogonal to each other as seen in Fig. 8b). In order to calculate the conversion factors, the tool spindle was locked and defined torques were applied onto the casing bar and the oscillating pole.

\section{RESULTS AND DISCUSSION}

\subsection{Influence of the process parameters on the machined profiles}

Influence of the cutting tool

In Fig. 9, the measured contours and the calculated profile areas are displayed in dependence of different cutting tools. Furthermore, the calculated profile surfaces are compared to a theoretical target profile area that was calculated using the measured stroke and the contour of the cam disk. 


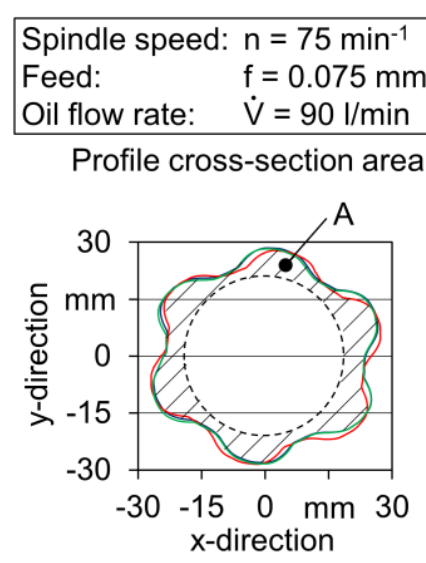

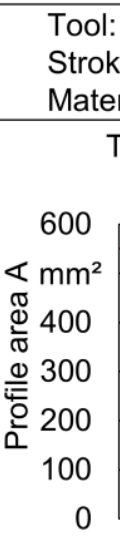

varied

$x=5 \mathrm{~mm}$ EN AW-6060

- Polished A $\quad$ Rounded B $\quad$ Chamfer C

Fig. 9: Plotted contour and profile area in dependency of the cutting tool.

The diagram shows no significant influence of the used tool regarding the machined profile surface. All calculated profile cross-section areas were approx. $\Delta \mathrm{A}=80 \mathrm{~mm}^{2}$ $(15 \%)$ lesser than the target profile area. One reason for this phenomenon could be the deflection of the tool path from the nominal tool path due to the process forces. The tool variation was conducted machining aluminium specimens, because of repeated failure of the polished tools in both steel alloy specimens. Due to the repeated failure of tools $A$ and $B$ in the steel materials, the experiments with varying parameters and materials can only be carried out with the chamfered tool C.

Influence of the feed and the material

The feed $f$ was varied while boring from $f=0.05 \mathrm{~mm}$ up to $\mathrm{f}=0.125 \mathrm{~mm}$ in $\Delta \mathrm{f}=0.025 \mathrm{~mm}$ steps. All three materials described in chapter 2 were machined. The cutting tool with the protective chamfer was used. A diagram comparing the calculated profile areas for each feed $f$ and material with the target profile areas is shown in Fig. 10.

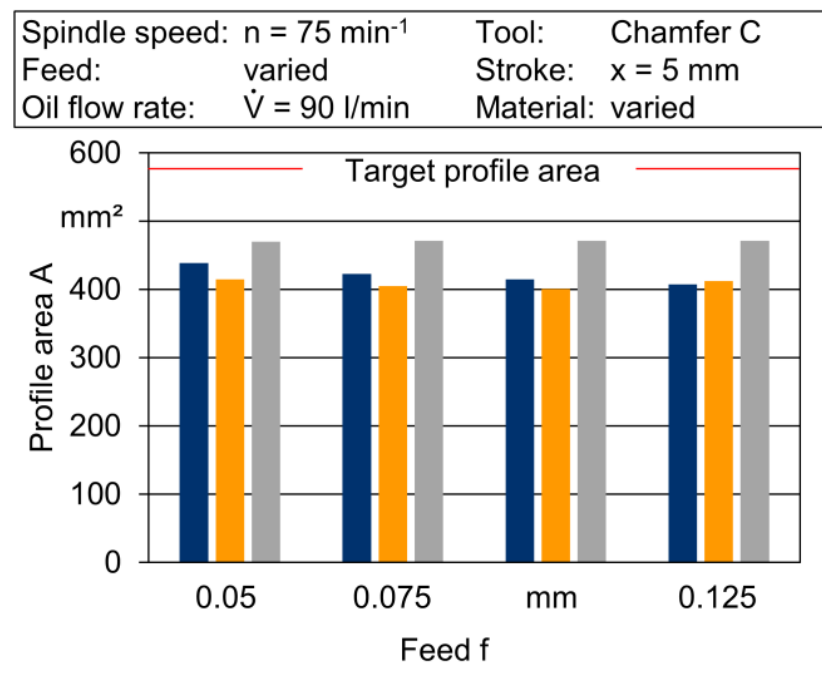
AISI $4140 \quad$ AISI $1060 \square \mathrm{EN} \mathrm{AW-6060}$
Fig. 10: Calculated profile area for varied feeds and
different materials.

The largest difference in profile area was linked to the material. Target profile area and EN AW-6060 profile area varied about $\Delta \mathrm{A}=80 \mathrm{~mm}^{2}(15 \%)$ as Fig. 9 showed before. $A$ variation of the feed $f$ had near influence on the machined aluminium surface profiles. Machining steel results in even lower profile areas than machining aluminium. For AISI 4140 the lowest profile are identified at a feed $\mathrm{f}=0.125 \mathrm{~mm}$ with $\Delta \mathrm{A}=140 \mathrm{~mm}^{2}(25 \%)$ difference to the target profile area. AISI 1060 shows the lowest profile area at a feed $\mathrm{f}=0.1 \mathrm{~mm}$ with $\Delta \mathrm{A}=150 \mathrm{~mm}^{2}(27 \%)$ difference to the target profile area. Differences in tensile strength and hardness between the steel alloys and the aluminium are most likely the reason for the different deviations to the target profile area. Since these properties affect the occurring process forces which could deflect the tool path from the nominal tool path.

Increasing the feed f while machining AISI 4140 resulted in a slight reduction of the profile area. Starting with a feed of $f=0.05 \mathrm{~mm}$ and a profile area of $A=440 \mathrm{~mm}^{2}$ the profile area gradually decreased. Increasing the feed up to $f=0.125 \mathrm{~mm}$ resulted in a profile area of $A=410 \mathrm{~mm}^{2}$, a reduction of $7 \%$. The feed $f$ affects the resulting cutting force as well, which may have led to a deflection of the tool path.

\section{Influence of the cutting speed}

The cutting speed $v_{c}$ is not constant due to the stroke, as described in chapter 2.2. Because of this characteristic, the constant spindle speed was used as the characteristic parameter. Tab. 3 shows the spindle speed $n$ and the corresponding cutting speed range.

Tab. 3: Process spindle speeds and corresponding cutting speed ranges

\begin{tabular}{|c|c|c|c|c|}
\hline $\begin{array}{c}\mathrm{n} \text { in } \\
\mathrm{min}^{-1}\end{array}$ & 50 & 75 & 100 & 125 \\
\hline $\begin{array}{c}v_{c} \text { in } \\
m / m i n\end{array}$ & $10 \ldots 12$ & $15 \ldots 18$ & $21 \ldots 24$ & $26 \ldots 30$ \\
\hline
\end{tabular}

The diagram shown in Fig. 11 compares the calculated profile areas for each spindle speed and material with the target profile area. It was not possible to generate reliable measurements for the highest spindle speed in AISI 4140 due to tool failure.

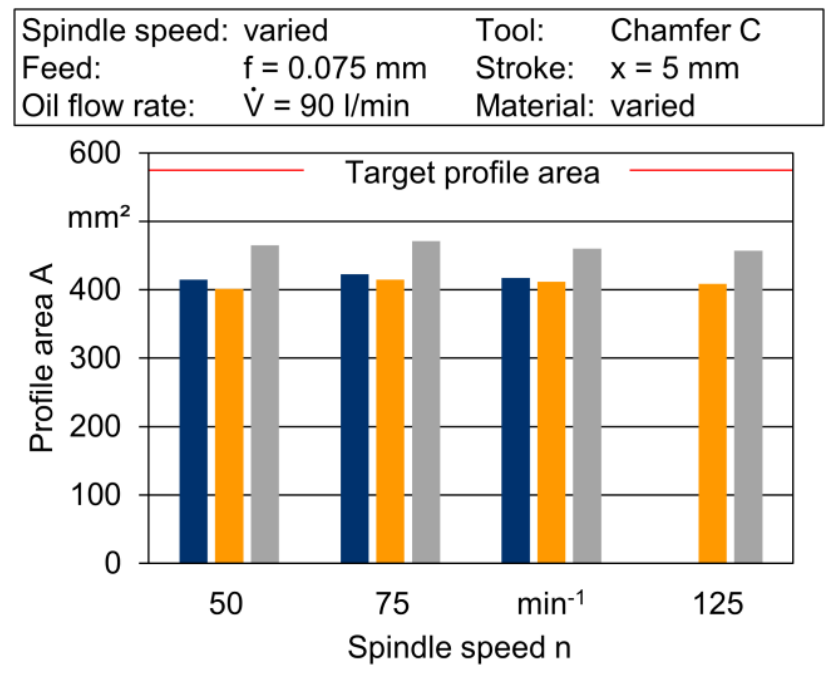

-AISI 4140 AISI 1060 EN AW-6060

Fig. 11: Calculated profile area for varied spindle speeds and different materials.

The diagram shows no direct trend or relationship between the calculated profile area and the cutting speed. The strong influence of the machined material is also confirmed in this series of tests. 


\subsection{Influence of the process parameters on the process forces}

Influence of the material

Torque measurements at the casing bar and the oscillating pole were conducted while machining the profile. Fig. 12 shows the torque of the two bars in the unloaded state and while machining different materials. The examined process time was $t=2 \mathrm{~s}$ corresponding to 1.5 revolutions. Both diagrams show the measured and the smoothed curves of the experiments. In contrast to the unloaded state, the measured torques on the casing bar are significant higher than the torques on the oscillating pole. Therefore, it is necessary that the casing bar and the oscillating pole are represented using different moment scales.

\begin{tabular}{llll|}
\hline Spindle speed: & $\mathrm{n}=50 \mathrm{~min}^{-1}$ & Tool: & Chamfer C \\
Feed: & $\mathrm{f}=0.075 \mathrm{~mm}$ & Stroke: & $\mathrm{x}=5 \mathrm{~mm}$ \\
Oil flow rate: & $\dot{\mathrm{V}}=90 \mathrm{l} / \mathrm{min}$ & Material: varied
\end{tabular}

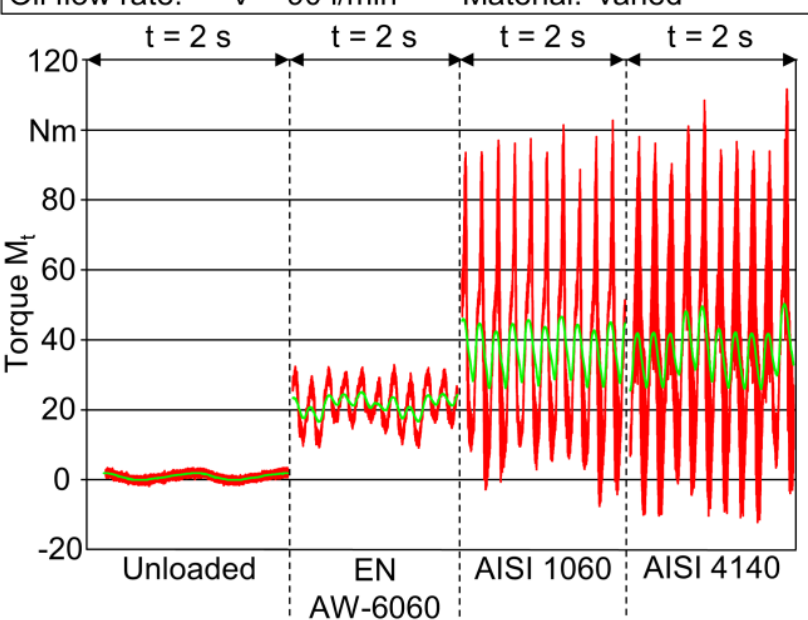

Materials



- Oscillating pole - Oscillating pole (smoothed)

Fig. 12: Measured torques depending on different materials.

The oscillating course of the curves originated form the varying depth of cut due to the stroke results in varying cutting forces, which cause an unsteady torque.

The torque on the oscillating pole showed significant differences, depending on the material. There were only minor differences between the unloaded state and the test with aluminium. The maximum torque variation $\Delta \mathrm{M}_{\mathrm{t}}=10 \mathrm{Nm}$ was the same for both measurements.

Between the aluminium and the steel alloys a difference in in torque variation was measured. While machining AISI 1060 the torque variation increased to $\Delta \mathrm{M}_{\mathrm{t}} \approx 15 \mathrm{Nm}$ and for AISI 4140 to $\Delta \mathrm{M}_{\mathrm{t}} \approx 18 \mathrm{Nm}$ due to the higher strength. The higher torque variations resulted from the higher process forces, which are generated during the machining of the steel materials. Both measuring records were wave-shaped. The pitches were also higher due to the higher minima and maxima. The measurements of the casing rod differ considerably in the loaded and unloaded condition. While the average value of the measurement record in the unloaded condition were just above $\mathrm{M}_{\mathrm{t}} \approx 0 \mathrm{Nm}$, the average value increased while machining aluminium to $\mathrm{M}_{\mathrm{t}} \approx 20 \mathrm{Nm}$. For the steel alloys the average value increased to $M_{t} \approx 40 \mathrm{Nm}$. The reason for the increase of the torque are higher cutting forces, due to material properties. The cutting force was applied through the casing rod, in the form of the torque.

\section{Influence of the feed}

The diagrams in Fig. 13 are, as shown in the evaluation before, composed of several parts. The $\mathrm{x}$-axis is divided into ranges which corresponds to the individual feeds. The examined process time was $t=1 \mathrm{~s}$ corresponding to 1.25 revolutions.
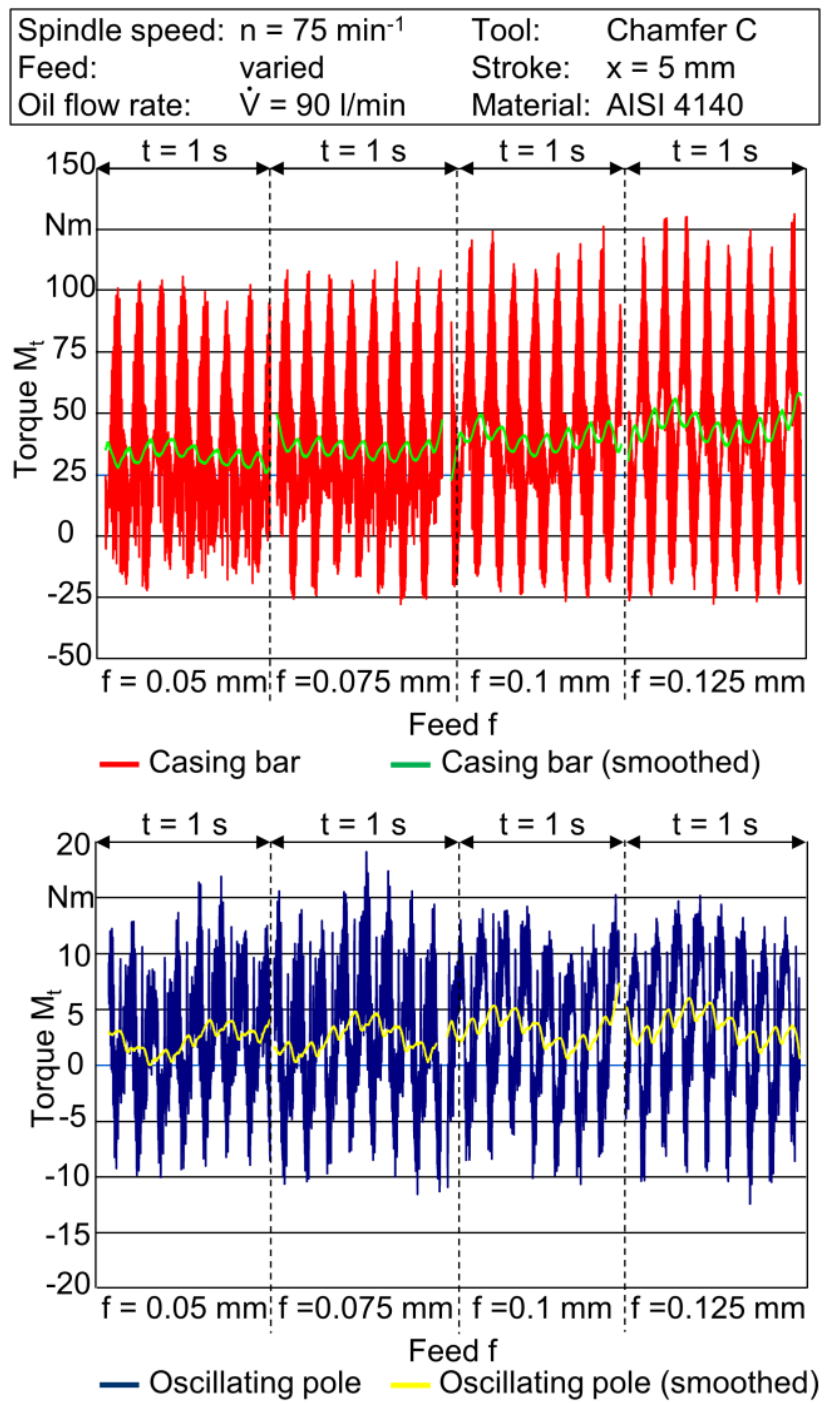

Fig. 13: Measured torques depending on different feeds.

The measuring record of the casing bar differs in the torque variation. At a feed of $f=0.05 \mathrm{~mm}$, the torque variation was $\Delta \mathrm{M}_{\mathrm{t}} \approx 120 \mathrm{Nm}$ with an average torque of $\mathrm{M}_{\mathrm{t}} \approx 30 \mathrm{Nm}$. Each increase in the feed $f$ also increases the range of variation and the average torque. At the highest feed of $f=0.125 \mathrm{~mm}$ the highest torque variation and average torque were 
measured $\Delta \mathrm{M}_{\mathrm{t}} \approx 155 \mathrm{Nm}$ and $\mathrm{M}_{\mathrm{t}} \approx 42 \mathrm{Nm}$, respectively. The increase in the feed f leads to an increase in the cutting force, which resulted in a greater torque acting on the casing bar.

The measuring records of the oscillating pole appear less noisy due to the increase in feed. However, the torque variation did not change due to the increase in feed. All measuring records had a torque variation of $\Delta \mathrm{M}_{\mathrm{t}} \approx 25 \ldots 30 \mathrm{Nm}$ and an average torque slightly above $\mathrm{M}_{\mathrm{t}} \approx 0 \mathrm{Nm}$.

\section{Influence of the cutting speed}

The cutting speed $v_{c}$ changes continuously despite constant spindle speed $\mathrm{n}$. Fig. 14 shows the measured torque while machining with varying spindle speed $n$. The defined diagram areas for the spindle speeds represent one revolution of the tool.

\begin{tabular}{llll}
\hline Spindle speed: varied & Tool: & Chamfer C \\
Feed: & $f=0.075 \mathrm{~mm}$ & Stroke: & $x=5 \mathrm{~mm}$ \\
Oil flow rate: & $\dot{V}=90 \mathrm{l} / \mathrm{min}$ & Material: & AISI 1060 \\
\hline
\end{tabular}
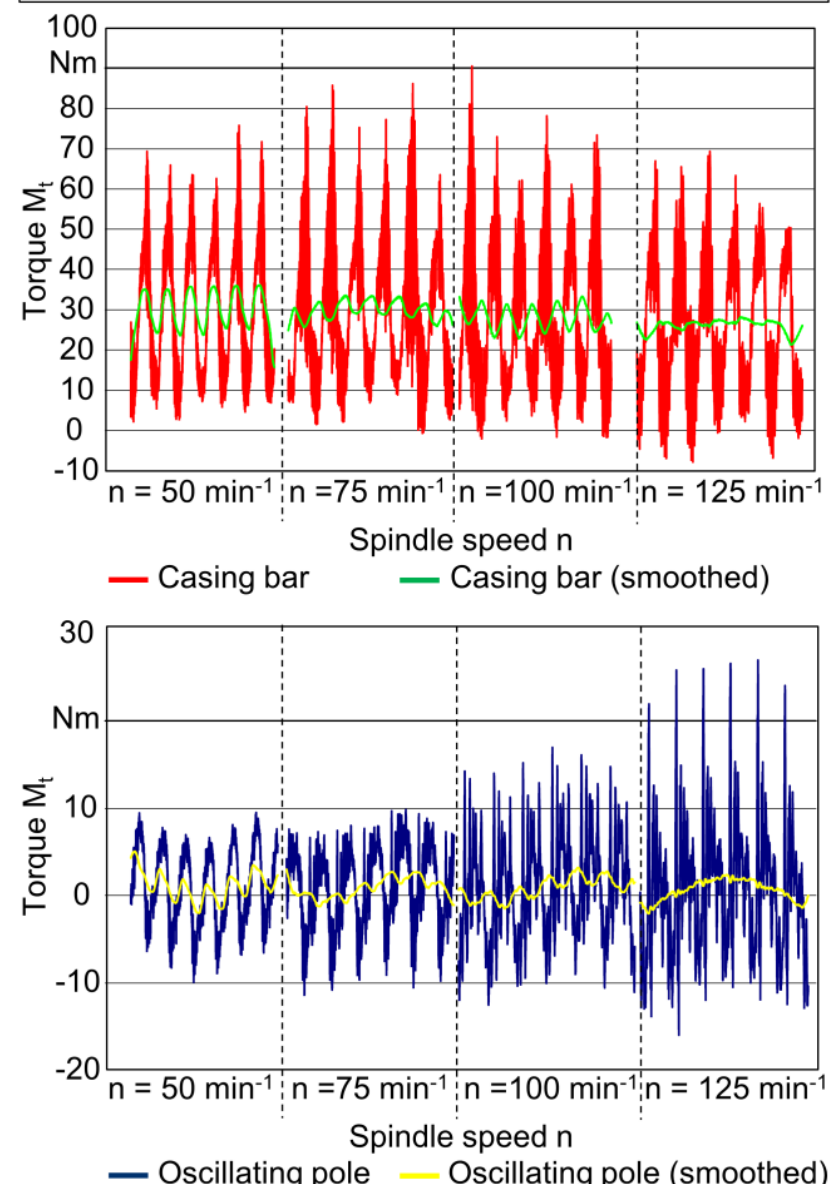

Fig. 14: Measured torques depending on different spindle speeds.

On the casing bar, no significant influence of cutting speed $\mathrm{v}_{\mathrm{c}}$ was determined. The average torque was $\mathrm{M}_{\mathrm{t}}=27 \pm 2 \mathrm{Nm}$ in all four measurements. At $\mathrm{n}=50 \mathrm{~min}^{-1}$ and $n=125 \mathrm{~min}^{-1}$, torque variation was $\Delta \mathrm{M}_{\mathrm{t}}=77 \pm 2 \mathrm{Nm}$. For the speeds $n=75 \mathrm{~min}^{-1}$ and $n=100 \mathrm{~min}^{-1}$, higher torque variation $\Delta \mathrm{M}_{\mathrm{t}}=90 \pm 2 \mathrm{Nm}$ were determined.

With increasing spindle speed $n$ or cutting speed $v_{c}$, the torque variation increased significantly. With a spindle speed of $n=50 \mathrm{~min}^{-1}$, a torque variation $\Delta M_{t}=18 \mathrm{Nm}$ was measured. During the speed increase to $\mathrm{n}=75 \mathrm{~min}^{-1}$, $\mathrm{n}=100 \mathrm{~min}^{-1}$ and $\mathrm{n}=125 \mathrm{~min}^{-1}$, the higher torque variations were measured to $\Delta M_{t}=20 \mathrm{Nm}, \Delta M_{t}=29 \mathrm{Nm}$ and $\Delta \mathrm{Mt}_{\mathrm{t}}=42 \mathrm{Nm}$, respectively. At the same time the average torque was oscillating around $\mathrm{M}_{\mathrm{t}}=0 \mathrm{Nm}$ in all measurements. The increasing torque variation, most likely, resulted from the dynamic behaviour of the oscillating pole and of the tool-/slide-drive. Due to the increasing spindle speed the speed and acceleration of the rail guided plate increase as shown in chapter 2.2. The rail guided plate is connected to the oscillation pole and thus the angular momentum of the oscillating pole increases. This led to a rise in torsion in the oscillating pole.

\section{SUMMARY}

In the first part of the studies, the influence of the process parameters on the machined profile was examined. It was shown that a cutting tool with a protective chamfer is necessary for steel machining. The results of the test series in EN AW-6060 showed no difference in the profile area for different cutting tool geometries. For an increasing feed $\mathrm{f}$, a decrease of the profile area was shown. The test series with varied spindle speed did not show any trend between the cutting speed $v_{c}$ and the profile area. In addition, it could be demonstrated that the material has the greatest influence on the resulting profile.

The results show, that increasing torques leads to smaller profile surfaces, most likely because of tool path deviation. After the exact adjustment of the process, it is possible to machine workpieces with a drilling depth of $2400 \mathrm{~mm}$. It was necessary to replace the cutting tool after a drilling depth of $800 \mathrm{~mm}$ to ensure a safe process. Due to the detailed analyses, a restart of the process could be realized. This process is very difficult to carry out due to the pitch of the workpiece and the torsion of the boring bar. The red mark in Fig. 15 shows the area of the restarted process.

\begin{tabular}{ll|}
\hline Material: & AISI 4140 \\
Oil flow rate: & $\dot{\mathrm{V}}=90 \mathrm{I} / \mathrm{min}$ \\
Feed: & $\mathrm{f}=0.075 \mathrm{~mm}$ \\
Cutting speed: & $\mathrm{v}_{\mathrm{c}}=11.56 \ldots 14.32 \mathrm{~m} / \mathrm{min}$ \\
Diameter: & $\mathrm{d}=46.2 \ldots 56.6 \mathrm{~mm}$ \\
Rotational speed: & $\mathrm{n}=80 \mathrm{~min}^{-1}$ \\
Drilling depth: & $\mathrm{I}_{\mathrm{t}}=2400 \mathrm{~mm}(3 \times 800 \mathrm{~mm})$ \\
Profile pitch: & $\mathrm{P}=500 \mathrm{~mm}$ \\
Machining time: & $\mathrm{t}_{\mathrm{h}}=3 \times 134 \mathrm{~min} \approx 6.7 \mathrm{~h}$ \\
\hline
\end{tabular}
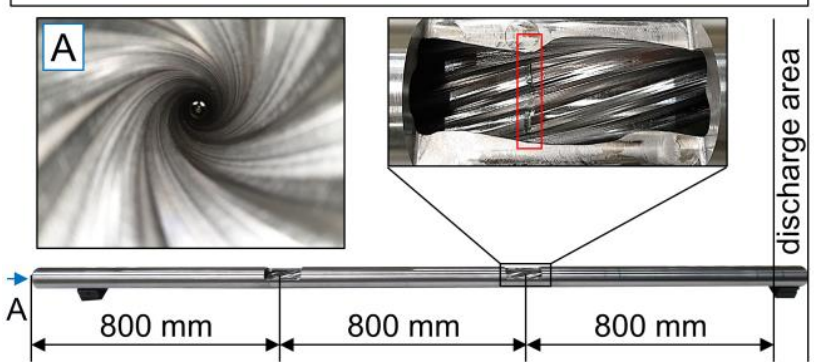

Fig. 15: Chamber bored workpiece with two tool changes after $I_{f}=800 \mathrm{~mm}$ and $I_{f}=1600 \mathrm{~mm}$ drilling depth.

\section{ACKNOWLEDGMENTS}

The authors would like to thank the "Federal Ministry for Economic Affairs and Energy" (BMWi) for funding the research ZIM-project "Development of a process to manufacture deep drillings with non-circular cross sections". Special thanks go to BGTB GmbH from Dortmund, whose expertise and support positively influenced the course of the project. 


\section{REFERENCES}

[Baker Hughes 2002] N.N.: Navi-Drill Motor Handbook. 9. Aufl. Baker Hughes Inc. 2002

[Biermann 2018] Biermann, D.; Bleicher, F.; Heisel, U.; Klocke, F.; Möhring, C.; Shih, A.: Deep hole drilling. CIRP Annals Volume 67, Issue 2, 2018, Pages 673-694.

[Bottos 2003] Bottos, R.D.; Underwood, L. D.: Method of making an internally profiled stator tube, United States Patent 6568076B2, 2003.

[Buse 1994] Buse, B.; Bergmann, K.; Fuß, H.: Flexible Innenbearbeitung mit rechnergesteuerten Bohrwerkzeugen. Spanende Fertigung 1, Vulkan-Verlag, Essen, 1994

[Delta 2019]; DELTA-TRADING GmbH Metallhandel. :AIMgSi0,5: EN AW-6060 -3.3206 - AIMgSi0,5 Werkstoffdatenblatt. http://www.deltatrading.de/fileadmin/edit/datenbl\%C3\%A4tter/EN_AW-

6060_-_3.3206_-_AlMgSi0_5_-_Werkstoffdatenblatt.pdf., 27.05.2017

[Denkena 2016] Denkena, B. et al.: Werkzeugentwicklung für die Statorherstellung. MM Maschinenmarkt, Ausgabe 8. Würzburg, 2016

[DIN EN ISO 286-1:2019-02] Geometrical product specifications (GPS) - ISO code system for tolerances on linear sizes - Part 1: Basis of tolerances, deviations and fits [Fuß 2016] Fuß, M.; Abrahams, H.; Buse, B.; Biermann, D.: Production of Deep Bore Holes with Non-Circular Profiles, Advanced Materials Research, Vol. 1140, pp. 197-204, 2016

[Heisel 1989] Heisel, U.; Ruzicka, G.: Auskammern durch Fräsen. Dima 43 6, pages 16-23, 1989

[Maurer 2000] Maurer, W.: Advanced Geothermal Turbodrill, Techn. Ber. U.S. Department of Energy, 2000.

[Saarstahl 2019a] Saarstahl AG: Werkstoff-Datenblatt 42CrMo4 - 42CrMoS4. http://www.saarstahl.com/ sag/downloads/download/11318, 27.05.2019

[Saarstahl 2019b] Saarstahl AG: Werkstoff-Datenblatt C60R (Cm60). https://www.saarstahl.com /sag/downloads/download/11018, 27.05.2019 